\title{
Cost-Effectiveness of Bridging Anticoagulation Among Patients with Nonvalvular Atrial Fibrillation
}

\author{
Matthew A. Pappas, MD, MPH ${ }^{1,2}$, Geoffrey D. Barnes, MD, MSc ${ }^{3}$, and Sandeep Vijan, MD, MS \\ ${ }^{1}$ Center for Value-Based Care Research, Medicine Institute, Cleveland Clinic, Cleveland, OH, USA; ${ }^{2}$ Department of Hospital Medicine, Medicine \\ Institute, Cleveland Clinic, Cleveland, $\mathrm{OH}$, USA; ${ }^{3}$ Frankel Cardiovascular Center, Department of Internal Medicine, University of Michigan Health \\ System, Ann Arbor, MI, USA; ${ }^{4}$ Division of General Internal Medicine, Department of Internal Medicine, University of Michigan Health System, Ann \\ Arbor, MI, USA.
}

BACKGROUND: Bridging anticoagulation is commonly prescribed to patients with atrial fibrillation during initiation and interruption of warfarin. Guidelines recommend bridging patients at high risk of stroke, while a recent randomized trial demonstrated overall harm in a population at comparatively low risk of ischemic stroke. Theory suggests that patients at high risk of stroke and low risk of hemorrhage may benefit from bridging, but data informing patient selection are scant.

OBJECTIVE: To estimate the utility and costeffectiveness of bridging anticoagulation among patients with nonvalvular atrial fibrillation, stratified by thromboembolic and hemorrhagic risk

DESIGN: Cost-effectiveness analysis with lifelong time horizon, from the perspective of a third-party payer

MAIN MEASURES: Quality-adjusted life years (QALYs) per bridged patient; US dollars per QALY gained

KEY RESULTS: Unselected patients with nonvalvular atrial fibrillation may be harmed by bridging anticoagulation. Hospital admission for bridging is almost never cost-effective, and generally harmful. Among patients carefully selected by both thromboembolic and hemorrhagic risks, outpatient bridging can be beneficial and cost-effective. Results were sensitive to how effectively heparin products reduce stroke risk.

CONCLUSIONS: Outpatient bridging anticoagulation can be beneficial and cost-effective for a subset of patients with nonvalvular atrial fibrillation during interruption or initiation of warfarin. Admission for bridging should be avoided.

KEY WORDS: Monte Carlo method; models, statistical; atrial fibrillation; thromboembolism; anticoagulants.

J Gen Intern Med 34(4):583-90

DOI: $10.1007 / \mathrm{s} 11606-018-4796-9$

(c) Society of General Internal Medicine 2019

Electronic supplementary material The online version of this article (https://doi.org/10.1007/s11606-018-4796-9) contains supplementary material, which is available to authorized users.

Received November 16, 2017

Revised June 14, 2018

Accepted November 28, 2018

Published online January 8, 2019

\section{INTRODUCTION}

Atrial fibrillation is a common and costly cardiac arrhythmia of increasing prevalence. Because atrial fibrillation significantly increases risk of thromboembolic stroke, it is commonly managed with anticoagulation, including warfarin. During initiation or interruption of warfarin, physicians often prescribe concomitant short-acting parenteral anticoagulants ("bridging" anticoagulation). The practice of bridging has been the topic of a recent randomized controlled trial (BRIDGE), registry-based studies (ORBIT-AF), and revisions to practice guidelines. ${ }^{1-3}$ This work has shown that, for most patients with atrial fibrillation, periprocedural parenteral anticoagulation causes patient harm.

Still, a number of questions regarding bridging remain unanswered. Patient-level risk of stroke and hemorrhagic complications vary widely, and high-risk patients have been underrepresented in prior trials. ${ }^{1}$ Significant heterogeneity of treatment effect is likely. Additionally, little published data has addressed bridging during warfarin initiation.

Use of direct oral anticoagulants (DOACs) has increased, but warfarin remains the most common oral anticoagulant, and bridging remains common., ${ }^{2,}, 5$ In an effort to allow nuanced clinical decision-making across the spectrum of risk, we recently projected the net clinical benefit of bridging anticoagulation. In that analysis, we suggested that carefully selected patients may benefit from bridging, even as most patients are likely harmed by the practice. ${ }^{6}$

Projections of net clinical benefit are subject to important limitations. Most notably, projections of net clinical benefit do not incorporate patient disutilities, such as the loss in quality of life from nonfatal bleeding, hospitalization, or use of an injected medication. Because bridging anticoagulation increases the risk of hemorrhagic complications, the impact of such events may outstrip the harm from ischemic stroke, as in other conditions where overall benefit is modest. ${ }^{7}$ Further, projections of net clinical benefit do not include costs of care. Even if bridging offers a benefit to carefully selected patients, that benefit may not be cost-effective.

Given the continued use of warfarin, continued use of bridging, and the wide range of underlying patient risks, we set out to estimate the utility and cost-effectiveness of bridging 
anticoagulation among patients with nonvalvular atrial fibrillation, compared with forgoing bridging, when warfarin is either newly initiated or interrupted.

\section{METHODS}

We have previously published a description of our microsimulation model predicting the net clinical benefit of bridging anticoagulation among patients with nonvalvular atrial fibrillation (hereafter, the Personalized Anticoagulation Decision-Making Assistance model, or PADMA). ${ }^{6}$ Building on that existing model, we added the disutility of bridging anticoagulation and the downstream consequences of each of the events (ischemic stroke, intracranial hemorrhage, and extracranial major hemorrhage) that we treated as endpoints in our earlier work, ultimately predicting the utility and costeffectiveness of bridging. A simplified schematic of our model is included in the online Supplemental Appendix. We simulated from a third-party payer perspective over a lifelong time horizon. We applied standard exponential discounting to both costs and utilities. All analyses were performed in version 13 of Stata (College Station, TX).

\section{Synthetic Population}

To generate a synthetic population that reflects the comorbidities and age distribution of a population of US patients with atrial fibrillation, we merged relevant variables from NHANES 2011-2012 (the most recent NHANES for which all pertinent comorbidities are available). We used multiple imputation to correct for missing variables and estimated creatinine clearance using the Chronic Kidney Disease Epidemiology Collaboration (CKD-EPI) equation. ${ }^{8,}{ }^{9}$ We then bootstrapped to national population estimates, by age and sex, to arrive at a hypothetical population of the USA. ${ }^{10}$ Because NHANES does not include atrial fibrillation, we applied sex- and age-specific prevalence rates from ATRIA. ${ }^{11}$ We then calculated risk scores $\left(\mathrm{CHADS}_{2}\right.$ or $\mathrm{CHA}_{2} \mathrm{DS}_{2}-\mathrm{VASc}$ and either HAS-BLED or HEMORR ${ }_{2}$ HAGES) for each patient in our synthetic population. ${ }^{12-15}$ Events during the bridging period were simulated in this synthetic population using the previously described PADMA model. ${ }^{6}$

\section{The PADMA Model}

A full description of our microsimulation model has been published previously. ${ }^{6}$ Briefly, the PADMA model uses perpatient risk scores to predict baseline event rates (either CHADS2 or CHA2DS2-VASc to predict a patient's baseline risk of stroke and either HAS-BLED or HEMORR2HAGES to predict a patient's baseline risk of hemorrhagic complications). It then samples trajectories of INR measurements on each day of warfarin initiation or interruption, estimates the changes in baseline risks for each patient at each day's INR, and returns the daily risk of three events: ischemic stroke, intracranial hemorrhage, and extracranial major hemorrhage.

Patient-specific risks can be further modified by bridging, which we defined as parenteral anticoagulation (either enoxaparin or unfractionated heparin) beginning either concomitant to warfarin (in the case of initiation) or five days after discontinuation, concomitant to warfarin reinitiation and after a procedure (in the case of interruption). In both cases, parenteral anticoagulation continues until a patient's INR reaches or exceeds 2.0. Finally, the risk of each event for each patient on each day is dichotomized using a stochastic process.

\section{Event Type, Severity, and Mortality}

Simulated patients who sustain an intracranial hemorrhage (ICH) have a type of ICH assigned (intracerebral, subarachnoid, or subdural) according to the probabilities of each subtype in the warfarin groups of the RE-LY and ROCKET-AF trials. ${ }^{16,}{ }^{17}$ We did not consider epidural hemorrhages. For patients who sustain an intracerebral hemorrhage, we drew severity (as measured by NIHSS) from a normal distribution matching the summary statistics published by the Get With the Guidelines-Stroke registry (GWTG) ${ }^{18}$ For patients who sustain a subarachnoid hemorrhage, we drew NIHSS from a gamma distribution to match the summary statistics published by GWTG. ${ }^{18}$ For patients who sustain an ischemic stroke, we bootstrapped NIHSS directly from the subset of patients enrolled in the NINDS tPA trial who had atrial fibrillation. ${ }^{19}$ For all patients who sustain stroke or intracranial hemorrhage, we estimated in-hospital mortality using previously published multifactorial risk prediction estimates. ${ }^{18,20,21}$ For extracranial major hemorrhage, we used previously cited point estimates of the case fatality rate of extracranial major hemorrhage in atrial fibrillation cohorts, bootstrapping to estimate the standard error of the mean. ${ }^{22,23}$

\section{Future Disability and Mortality}

For hypothetical patients who survive to hospital discharge, we predicted modified Rankin scores (mRS) 3 months following the simulated event to estimate long-term morbidity. For simulated patients who sustained intracranial hemorrhages, we followed the rates of disability published by the ATRIA cohort, assuming that "minor disability" was evenly distributed between mRS of 1 and 2, that "major disability" was evenly distributed among mRS of 3-5, and no differences in rates of disability based on type of intracranial hemorrhage. ${ }^{24}$ For simulated patients who sustained ischemic strokes, we created an ordered logistic regression derived from NINDS t-PA trial data (further described in the online Supplemental Appendix). ${ }^{19}$ For all patients who survive to discharge, we calculated post-event life expectancy using published life tables and applying mRSspecific hazard ratios for patients who sustained ischemic stroke or intracranial hemorrhage. ${ }^{25,}{ }^{26} \mathrm{We}$ assumed that extracranial major hemorrhage did not cause appreciable long-term disability or impact mortality following hospital discharge. ${ }^{24}$ 


\section{Disutilities}

We sampled expected length of stay for each event from the 2012 National Inpatient Sample (NIS). ${ }^{27}$ We then estimated the disutility of hospitalization as a function of length of stay; further detail regarding this estimate can be found in the online Supplemental Appendix. We used a baseline utility for this patient population of 0.988 , and estimated long-term disutilities conditioned on mRS. ${ }^{28,}{ }^{29}$ We assumed a small disutility for daily LMWH injections. We discounted all future qualityadjusted life years (QALYs).

\section{Costs}

We estimated the direct costs of outpatient bridging using doses of enoxaparin calculated based on patient weight and treatment duration, and assuming 15 min of nursing time for patient teaching. ${ }^{30,31}$ We directly sampled costs of hospitalization from NIS by principal diagnosis, deflated by the costto-charge ratio. ${ }^{27}$ We estimated costs of long-term care as a lognormal distribution, conditioned by $\mathrm{mRS}$ and discounted over the patient's remaining life expectancy. ${ }^{32}$ We discounted all costs to 2016 US dollars.

\section{Discounting}

It is a premise of economic and decision analyses that humans would rather receive a benefit today than in the future. In keeping with the last few decades of cost-effectiveness analyses, we applied standard exponential discounting to both costs and utilities. Also in keeping with decades of economic analyses, we have assumed a discount rate of 3\%. That is, $\$ 103$ one year in the future is equivalent to $\$ 100$ now; 1.03 days in perfect health one year in the future is equivalent to one day in perfect health now. To investigate sensitivity to this assumption, we used a uniform distribution centered at a discount rate of $3 \%$, rather than a point estimate. We did not consider hyperbolic or other dynamic models of time preference.

\section{Sensitivity Analyses}

In sensitivity analyses, we varied the risk scores used to estimate underlying risks of hemorrhagic and thromboembolic complications $\left(\mathrm{CHADS}_{2}\right.$ vs. $\mathrm{CHA}_{2} \mathrm{DS}_{2}$-VASc, HAS-BLED vs. HEMORR ${ }_{2} \mathrm{HAGES}$ ). For easier comparison with other data published regarding bridging, we used $\mathrm{CHADS}_{2}$ and HAS-BLED scores in our base-case scenario. We also varied the number of days during which bridging is prescribed, the annual discount rate, and whether simulated patients with an estimated glomerular filtration rate (eGFR) below $30 \mathrm{~mL} / \mathrm{min}$ are admitted for inpatient bridging with unfractionated heparin until the patient's INR reaches 2.0. In our base-case analysis, we assumed that patients whose eGFR is below $30 \mathrm{~mL} / \mathrm{min}$ are admitted for bridging with unfractionated heparin, while others are bridged in the outpatient setting. Separate analyses inpatient-only and outpatient-only bridging, with reduced-dose LMWH prescribed for patients of compromised renal function. We have previously varied other parameters in the PADMA model, and have not herein varied parameters to which the model is insensitive. ${ }^{6}$ Sensitivity analyses that materially changed our conclusions are discussed in further detail below; others are included in the online Supplemental Appendix. We also constructed a meta-model (a regression model of our microsimulation model's output) to demonstrate sensitivity to those input parameters which could be used to further personalize care, including discount rate, cost of LMWH, and costs of nursing time. Model input parameters are summarized in Tables 1 and 2.

\section{RESULTS}

In our base-case simulation of bridging during warfarin interruption, bridging conferred marginal harm in unselected patients, with a median per-patient loss of 0.1 quality-adjusted days of life and a mean per-patient loss of approximately 3.7 quality-adjusted days of life. In our base-case simulation of bridging during warfarin initiation, bridging again conferred marginal harm for unselected patients, with a median perpatient loss of approximately 0.04 quality-adjusted day of life and a mean per-patient loss of approximately 2.0 qualityadjusted days of life. For unselected patients with nonvalvular atrial fibrillation, bridging leads to net harm when either initiating or interrupting warfarin.

In our stratified analysis, carefully selected patient subgroups receive net benefit from bridging. Results are shown in Tables 3 (utility analysis) and 4 (cost-effectiveness) for our base-case simulation of warfarin initiation. However, the disutility of hospital admission for bridging reduced or exceeded the possible benefit of bridging. Hospital admission for bridging was therefore generally harmful, and was not costeffective for any group (mean, $\$ 8.7$ million per QALY; minimum, \$1.2 million per QALY). Because inpatient bridging was essentially never helpful or cost-effective, the remainder of our results are presented for outpatient-only bridging, with dose-reduced LMWH depending on renal function.

Results of our outpatient-only cost-effectiveness analysis during warfarin initiation are presented in Table 5 , again stratified by baseline risk of stroke and hemorrhage. In general, patients at high baseline risk of stroke and low baseline risk of hemorrhagic complications may derive net benefit from outpatient bridging. Compared with the base-case analysis, fewer patient subgroups were harmed by bridging, and bridging achieved customary costeffectiveness thresholds in more subgroups.

Analogous results for outpatient bridging during interruption of warfarin are shown in Table 6. Similarly, outpatient bridging anticoagulation meets commonly accepted cost-effectiveness thresholds only for patients selected by risk of both ischemic and hemorrhagic complications. Analogous tables using other combinations of risk scores, for both initiation and interruption, can be found in the online Supplemental Appendix. 
Table 1 Summary of Model Input Parameters: Fixed and Sampled Inputs

\begin{tabular}{|c|c|c|c|}
\hline Input parameter & Base-case estimate & Sensitivity analyses & Reference(s) \\
\hline Age and sex of US population & U.S. Census & - & 10 \\
\hline $\begin{array}{l}\text { Age- and sex-specific prevalence of } \\
\text { atrial fibrillation }\end{array}$ & ATRIA & - & 11 \\
\hline $\begin{array}{l}\text { Age- and sex-specific prevalence } \\
\text { and covariation of stroke risk factors }\end{array}$ & NHANES & - & 8 \\
\hline Annual incidence of ischemic stroke & $\begin{array}{l}\text { Fixed for each } \mathrm{CHADS}_{2} \text { score }(0.6 \% \\
\text { to } 14.6 \%)\end{array}$ & Fixed for each $\mathrm{CHA}_{2} \mathrm{DS}_{2}$-Vasc score $(0.2 \%$ to $14.4 \%)$ & 13,33 \\
\hline $\begin{array}{l}\text { Annual incidence of intracranial } \\
\text { hemorrhage }\end{array}$ & Fixed for each HAS-BLED score & $\begin{array}{l}\text { Rates fixed by HAS-BLED score without regression } \\
\text { smoothing; fixed for each HEMORR }{ }_{2} \text { HAGES score } \\
(0.1 \% \text { to } 4 \%)\end{array}$ & 13,33 \\
\hline $\begin{array}{l}\text { Annual incidence of extracranial } \\
\text { major hemorrhage }\end{array}$ & $\begin{array}{l}\text { Fixed for each HAS-BLED score } \\
(0.5 \% \text { to } 14.5 \%)\end{array}$ & $\begin{array}{l}\text { Fixed for each HEMORR }{ }_{2} \text { HAGES score }(0.4 \% \text { to } \\
21.1 \%)\end{array}$ & 13,33 \\
\hline Subtypes of intracranial hemorrhage & $\begin{array}{l}65 \% \text { intracerebral, } 6 \% \text { subarachnoid, } \\
29 \% \text { subdural }\end{array}$ & - & 16,17 \\
\hline $\begin{array}{l}\text { Duration of bridging during } \\
\text { outpatient initiation }\end{array}$ & 7 days & 5 or 10 days & Assumed \\
\hline $\begin{array}{l}\text { Duration of bridging during } \\
\text { outpatient resumption }\end{array}$ & 5 days & 7 or 10 days & Assumed \\
\hline $\begin{array}{l}\text { Duration of bridging during } \\
\text { inpatient admission }\end{array}$ & Until patient's INR $\geq 2.0$ & 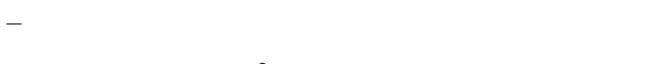 & Assumed \\
\hline $\begin{array}{l}\text { Trajectories of INR after initiation or } \\
\text { resumption of warfarin }\end{array}$ & $\begin{array}{l}\text { Sampled from clinical warfarin } \\
\text { initiation in COAG trial }\end{array}$ & Sampled from $\mathrm{MAQI}^{2}$ registry & 34,35 \\
\hline $\begin{array}{l}\text { Relative risk of ischemic stroke } \\
\text { during initiation (a hypercoagulable } \\
\text { state) }\end{array}$ & 1 (no hypercoagulable state) & Varies by day after initiation; normal on each day & 36 \\
\hline Location of bridging & $\begin{array}{l}\text { Outpatient only, with dose } \\
\text { adjustments based on weight and } \\
\text { renal function }\end{array}$ & Inpatient if eGFR $<30 \mathrm{~mL} / \mathrm{min}$; inpatient only & Assumed \\
\hline $\begin{array}{l}\text { Inpatient mortality following } \\
\text { ischemic or hemorrhagic stroke }\end{array}$ & Predicted & - & 18,20 \\
\hline $\begin{array}{l}\text { Inpatient mortality following } \\
\text { subdural hemorrhage }\end{array}$ & Predicted & - & 21 \\
\hline $\begin{array}{l}\text { Length of stay, conditioned on } \\
\text { diagnosis }\end{array}$ & Sampled & - & 27 \\
\hline $\begin{array}{l}\text { Hazard ratio for long-term mortality } \\
\text { following event, } \mathrm{mRS} \leq 2\end{array}$ & 1.7 & - & 25 \\
\hline $\begin{array}{l}\text { Hazard ratio for long-term mortality } \\
\text { following event, } \mathrm{mRS}=3 \text { or } 4\end{array}$ & 2.9 & - & 25 \\
\hline $\begin{array}{l}\text { Hazard ratio for long-term mortality } \\
\text { following event, } \mathrm{mRS} 5\end{array}$ & 8.3 & - & 25 \\
\hline Baseline probability of death by age & Varies & - & 26 \\
\hline $\begin{array}{l}\text { Cost of hospitalization following an } \\
\text { event, by primary diagnosis }\end{array}$ & Sampled & - & 27 \\
\hline $\begin{array}{l}\text { Future mRS following ischemic } \\
\text { stroke }\end{array}$ & Predicted & - & 19 \\
\hline $\begin{array}{l}\text { Future mRS following ICH, } \\
\text { assuming survival to discharge }\end{array}$ & $\begin{array}{l}13.8 \% \text { each mRS } 0-2,19.5 \% \text { each } \\
\text { mRS 3-5 }\end{array}$ & - & 24 \\
\hline
\end{tabular}

Our meta-model suggested that our results are most sensitive to age, discount rate, and the annual cost of long-term care and comparatively insensitive to the disutility of LMWH (in the range of our analysis) or the cost of nursing time. In the range here considered for the direct cost of LMWH $(95 \% \mathrm{CI}$, \$162-\$350), medication cost had only a modest effect. Results of our meta-model can be found in the online Supplemental Appendix. In general, among patient groups who stand to

Table 2 Summary of Model Input Parameters: Continuously Varying Input Parameters

\begin{tabular}{|c|c|c|c|c|}
\hline Input parameter & Mean (median) & sd (IQR) & Distribution & Reference(s) \\
\hline Severity of ischemic strokes (NIHSS) & 16.2 & 7.0 & Normal & 18,20 \\
\hline Severity of intracerebral hemorrhages (NIHSS) & 9 & $(3-19)$ & Normal & 18 \\
\hline Severity of subarachnoid hemorrhages (NIHSS) & 3 & $(0-11)$ & Gamma & 18 \\
\hline Odds ratio for ischemic stroke with bridging, base case & 0.14 & 0.02 & Normal & Theorized; see text \\
\hline Relative risk for hemorrhagic events with bridging & 3.86 & 1.55 & Normal & \\
\hline Starting INR for interruption simulations & 2.42 & 0.52 & Normal & 38 \\
\hline Annual cost of long-term care, $\mathrm{mRS}<3$ & $£ 942$ & $£ 3765$ & Lognormal & 39 \\
\hline Annual cost of long-term care, $\mathrm{mRS}=3$ or 4 & $£ 10,646$ & $£ 19,068$ & Lognormal & 39 \\
\hline Annual cost of long-term care, $\mathrm{mRS}=5$ & $£ 21,335$ & $£ 22,463$ & Lognormal & 39 \\
\hline Exchange rate, GBP to USD & 1.61 & 0.18 & Normal & 40 \\
\hline Cost of hospitalization for bridging, per day & $\$ 1314$ & $\$ 34$ & Normal & 27 \\
\hline Cost of nursing time, per hour & 33.23 & 9.70 & Lognormal & 30 \\
\hline Hospital mortality following extracranial major hemorrhage & $9.5 \%$ & $3.4 \%$ & Normal & 22,23 \\
\hline Discount rate & $3 \%$ & $1.7 \%$ & Uniform $(0-6 \%)$ & Assumed \\
\hline
\end{tabular}


Table 3 QALYs Conferred Per 100,000 Patients Bridged During Warfarin Initiation, with Renal Failure Patients (eGFR $<30$ mL/min) Admitted for Bridging and Others Bridged as Outpatients

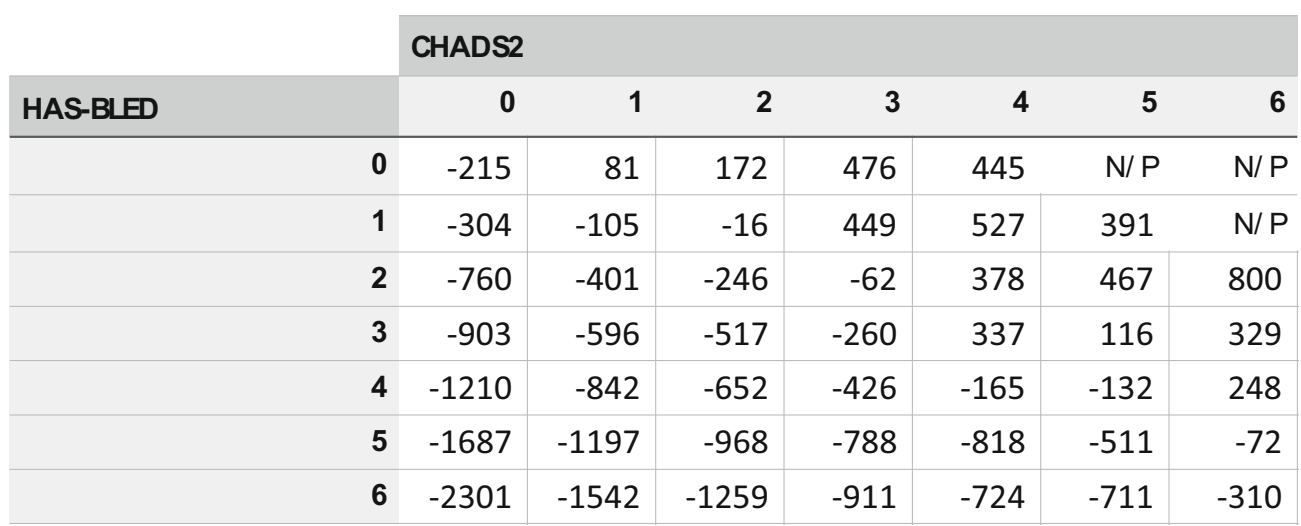

Positive numbers (in shaded cells) represent net benefit, while negative numbers represent net harm. Cells with combinations of scores that are not possible are designated by "N/P"

receive benefit from bridging, younger patients with high discount rates received less benefit (or harm), while patients at more advanced ages or with lower discount rates received benefit. Those two variables could potentially be used to further personalize bridging among patients beyond underlying risk, though our model results were far more robust to underlying stroke and hemorrhage risk.

Also as in prior work, our results are highly sensitive to the odds ratio for arterial thromboembolism with bridging. ${ }^{6}$ If observational data is used to estimate the efficacy of heparin products instead of the theory-driven estimate in our base case, no patients benefit from bridging in any scenario. ${ }^{37}$ Additional results, including utility and costeffectiveness analyses using the $\mathrm{CHA}_{2} \mathrm{DS}_{2}$-VASc and HEMORR ${ }_{2}$ HAGES scoring systems, are included in the online Supplemental Appendix.

\section{DISCUSSION}

Our results suggest that outpatient bridging can be beneficial and cost-effective for patients carefully selected on both ischemic and hemorrhagic risk, even though it is harmful for unselected patients. They add nuance to existing data and offer appropriate criteria by which patients might be selected for bridging. They reconcile theory (which would suggest that patients at high risk of stroke and low risk of hemorrhage might benefit) with existing data (which has shown net harm in unselected patients).

Our findings are complementary to the results of the BRIDGE trial. Whereas BRIDGE found no reduction in stroke risk and an increase in hemorrhagic complications, the trial included few patients at elevated stroke risk, and lacked sufficient power to stratify along both ischemic and hemorrhagic risk. In this microsimulation analysis, we have

Table 4 Cost-Effectiveness of Bridging During Warfarin Initiation, with Renal Failure Patients (eGFR $<30$ mL/min) Admitted for Bridging and Others Bridged as Outpatients

\begin{tabular}{|c|c|c|c|c|c|c|c|c|}
\hline \multirow[b]{2}{*}{ HAS-BLFD } & \multicolumn{8}{|c|}{$\mathrm{CHADS}_{2}$} \\
\hline & & 0 & 1 & 2 & 3 & 4 & 5 & 6 \\
\hline & 0 & & 274 & 479 & 182 & 134 & $\mathrm{~N} / \mathrm{P}$ & $\mathrm{N} / \mathrm{F}$ \\
\hline & 1 & & & & 483 & 163 & 154 & $\mathrm{~N} / \mathrm{F}$ \\
\hline & 2 & & & & & 367 & 232 & 47 \\
\hline & 3 & & & & & & & 1608 \\
\hline & 4 & & & & & & & 88 \\
\hline & 5 & & & & & & & \\
\hline & 6 & & & & & & & \\
\hline
\end{tabular}

Each cell shows the mean cost, in thousands of dollars per QALY, of bridging patients with that combination of risk scores. Shaded cells reach customary cost-effectiveness thresholds. Blank cells represent risk score combinations where bridging is harmful. Cells with combinations of scores that are not possible are designated by "N/P" 
Table 5 Cost-Effectiveness of Outpatient-Only Bridging During Warfarin Initiation

\begin{tabular}{|rrrrrrrrr} 
& & CHADS $_{2}$ & & & & & & \\
HAS-BLFD & & $\mathbf{0}$ & $\mathbf{1}$ & $\mathbf{2}$ & $\mathbf{3}$ & $\mathbf{4}$ & $\mathbf{5}$ & $\mathbf{6}$ \\
\hline & $\mathbf{0}$ & & 269 & 149 & 86 & 48 & $\mathrm{~N} / \mathrm{P}$ & $\mathrm{N} / \mathrm{P}$ \\
\hline $\mathbf{1}$ & & & 1025 & 155 & 65 & 37 & $\mathrm{~N} / \mathrm{P}$ \\
\hline $\mathbf{2}$ & & & & 260 & 139 & 267 \\
\hline $\mathbf{3}$ & & & 255 & 689 & 483 \\
\hline $\mathbf{5}$ & & & & & & \\
\hline $\mathbf{6}$ & & & & & & \\
\hline
\end{tabular}

Each cell shows the mean cost, in thousands of dollars per QALY, of bridging patients with that combination of risk scores. Shaded cells reach customary cost-effectiveness thresholds. Blank cells represent risk score combinations where bridging is harmful. Cells with combinations of scores that are not possible are designated by "N/P"

reinforced BRIDGE's finding of harm among unselected patients. More importantly, we suggest that carefully selected patients may nonetheless benefit from bridging and that the practice of bridging is likely cost-effective at usually accepted thresholds for carefully selected patients outside the hospital.

We have also been able to define the appropriate setting for bridging, if it is to be prescribed. In our analyses, hospital admission for bridging was essentially never cost-effective, for either initiation or interruption of warfarin. Moreover, the disutility of hospitalization overwhelmed the small average benefit of bridging, leading to net harm in almost all patient groups. Even without accounting for nosocomial infections or other iatrogenesis from hospital admission, our results argue against inpatient bridging when the sole indication is stroke prevention among patients with nonvalvular atrial fibrillation.

Our work suggests a number of ways in which clinicians could personalize decision-making when bridging therapy is considered. First, bridging should only be offered to patients after consideration of both hemorrhagic and thromboembolic risk. Selecting patients along either thromboembolic or hemorrhagic risk, but not both, would lead to subgroups who would be predictably harmed. We present tables, both here and in the online Supplemental Appendix, to refine patient-level predictions about potential net benefit using four combinations of risk scores. Second, we note that, even when stratifying by underlying risk of stroke and hemorrhagic complications, younger patients who are more interested in immediate benefit than long-term benefit (i.e., with higher discount rates) have less marginal benefit. Clinicians may wish to forego bridging in young patients who are very present-biased, even if they are in a risk group that stands to benefit from bridging. Third, we note that the predicted benefit of bridging does not meet usual cost-effectiveness thresholds for most subgroups of patients; physicians' roles as financial stewards may further restrict patients for whom bridging is recommended. ${ }^{41}$ Fourth, we suggest that hospital admission for bridging, even when patients are

Table 6 Cost-Effectiveness of Outpatient-Only Bridging During Warfarin Interruption

\begin{tabular}{|rrrrrrrrr} 
& & CHADS $_{2}$ & & & & & & \\
\hline HAS-BLF & & $\mathbf{0}$ & $\mathbf{1}$ & $\mathbf{2}$ & $\mathbf{3}$ & $\mathbf{4}$ & $\mathbf{5}$ & $\mathbf{6}$ \\
\hline $\mathbf{0}$ & & 275 & 182 & 71 & 38 & $\mathrm{~N} / \mathrm{P}$ & $\mathrm{N} / \mathrm{P}$ \\
\hline $\mathbf{1}$ & & & & 152 & 52 & 41 & $\mathrm{~N} / \mathrm{P}$ \\
\hline $\mathbf{2}$ & & & 170 & 139 & 32 \\
\hline $\mathbf{4}$ & & & 385 & 570 & \\
\hline $\mathbf{5}$ & & & & & & \\
\hline $\mathbf{6}$ & & & & & & & \\
\hline
\end{tabular}

Each cell shows the mean cost, in thousands of dollars per QALY, of bridging patients with that combination of risk scores. Shaded cells reach customary cost-effectiveness thresholds. Blank cells represent risk score combinations where bridging is harmful. Cells with combinations of scores that are not possible are designated by "N/P" 
carefully selected based on underlying risk, is usually harmful and almost never cost-effective.

This work is subject to a number of important limitations. First, as with all utility and cost-effectiveness analyses, QALYs gained or lost are a mathematical abstraction. Predictions regarding QALYs cannot be readily validated against existing datasets; rather, the validity of such predictions is generally assessed based on model content, structure, input parameters, and sensitivity analyses. ${ }^{42}$ Second, available data required that we make a number of assumptions. For example, we have assumed that underlying event risks are accurately estimated by existing prediction scores, even though each of these tools has limited predictive ability. And finally, this work highlights the discrepancy between theory and data regarding the effectiveness of heparin products in preventing arterial thromboembolism. If heparin products are as effective as warfarin, our results can guide bridging. If heparin is only as effective as observational data has suggested, bridging should be abandoned altogether. ${ }^{6,37}$

Despite these limitations, this work holds a number of implications for clinical practice. Use of DOACs is increasing, but warfarin remains the most common oral anticoagulant, and poor renal function is frequently considered a contraindication to DOAC use. We anticipate that warfarin prescriptions will continue and believe this work can inform decisions regarding bridging in such patients.

We would also caution that our findings should not be extrapolated to patients for whom immediate anticoagulation is warranted (such as acute venous thromboembolism) or to patients with other indications for anticoagulation. Further, our finding that admission for bridging is never cost-effective should not preclude bridging for patients with other indications for hospitalization. For example, our model predicts cost-effective net benefit for a patient with a $\mathrm{CHADS}_{2}$ score of 6 and a HAS-BLED score of 2. If anticoagulation was initiated while such a patient was hospitalized for another reason, bridging may be justifiable during the inpatient stay.

In summary, we here suggest that outpatient bridging anticoagulation can be helpful and cost-effective for selected patients with atrial fibrillation, and provide nuanced and quantitative estimates of net benefit for use in patient selection.

Corresponding Author: Matthew A. Pappas, MD, MPH; Center for Value-Based Care Research, Medicine Institute Cleveland Clinic, Cleveland, OH, USA (e-mail: pappasm@ccf.org).

\section{Compliance with Ethical Standards:}

Conflict of Interest: $D r$. Barnes has received grant funding from NIH/ NHLBI (KO1HL135392) and Blue Cross-Blue Shield of Michigan, and BMS/Pfizer, as well as consulting fees from BMS/Pfizer, Portola, and Janssen. All remaining authors declare that they do not have conflict of interest.

Publisher's Note: Springer Nature remains neutral with regard to jurisdictional claims in published maps and institutional affiliations.

\section{REFERENCES}

1. Douketis JD, Spyropoulos AC, Kaatz S, et al. Perioperative bridging anticoagulation in patients with atrial fibrillation. N Engl J Med. 2015;373(9):823-833. https://doi.org/10.1056/NEJMoa1501035.

2. Steinberg BA, Peterson ED, Kim S, et al. Use and outcomes associated with bridging during anticoagulation interruptions in patients with atrial fibrillation: findings from the Outcomes Registry for Better Informed Treatment of Atrial Fibrillation (ORBIT-AF). Circulation. 2015;131(5):488-494. https://doi.org/10.1161/ CIRCULATIONAHA.114.011777.

3. Doherty JU, Gluckman TJ, Hucker WJ, et al. 2017 ACC expert consensus decision pathway for periprocedural management of anticoagulation in patients with nonvalvular atrial fibrillation: a report of the American College of Cardiology Clinical Expert Consensus Document Task Force. J Am Coll Cardiol. 2017;69(7):871-898. https:// doi.org/10.1016/j.jacc.2016.11.024.

4. Barnes GD, Lucas E, Alexander GC, Goldberger ZD. National trends in ambulatory oral anticoagulant use. Am J Med. 2015;128(12):13005.e1302. https://doi.org/10.1016/j.amjmed.2015.05.044.

5. Awker AL, Bell MA, McGraw M, Klein MA. Impact of educational intervention on management of periprocedural anticoagulation. Am J Health Syst Pharm. 2017;74(23 Supplement 4):S95-S101. https://doi. org/10.2146/ajhp160726.

6. Pappas MA, Barnes GD, Vijan S. Personalizing bridging anticoagulation in patients with nonvalvular atrial fibrillation-a microsimulation analysis. J Gen Intern Med. 2017;32(4):464-470. https://doi.org/10.1007/ s11606-016-3932-7.

7. Vijan S, Sussman JB, Yudkin JS, Hayward RA. Effect of patients' risks and preferences on health gains with plasma glucose level lowering in type 2 diabetes mellitus. JAMA Intern Med. 2014;174(8):1227-1234. https://doi.org/10.1001/jamainternmed.2014.2894.

8. National Health and Nutrition Examination Survey Data (NHANES) 2011-2012. U.S. Department of Health and Human Services, Centers for Disease Control and Prevention, National Center for Health Statistics (NCHS). Available at: https://wwwn.cdc.gov/nchs/nhanes/ continuousnhanes/default.aspx?BeginYear=2011. Accessed: 26 Nov 2018.

9. Levey AS, Stevens LA, Schmid CH, et al. A new equation to estimate glomerular filtration rate. Ann Intern Med. 2009;150(9):604-612.

10. United States Census Bureau. 2014 national population projections tables. Available at: https://www.census.gov/data/tables/2014/demo/ popproj/2014-summary-tables.html. Accessed: 26 Nov 2018.

11. Go AS, Hylek EM, Phillips KA, et al. Prevalence of diagnosed atrial fibrillation in adults: national implications for rhythm management and stroke prevention: the AnTicoagulation and Risk Factors in Atrial Fibrillation (ATRIA) Study. JAMA. 2001;285(18):2370-2375.

12. Gage BF, Waterman AD, Shannon W, Boechler M, Rich MW, Radford MJ. Validation of clinical classification schemes for predicting stroke. JAMA. 2001;285(22):2864-2870. https://doi.org/10.1001/jama.285.22. 2864.

13. Friberg L, Rosenqvist M, Lip GYH. Evaluation of risk stratification schemes for ischaemic stroke and bleeding in 182678 patients with atrial fibrillation: the Swedish Atrial Fibrillation cohort study. Eur Heart J. 2012;33(12):1500-1510. https://doi.org/10.1093/eurheartj/ehr488.

14. Lip GYH, Nieuwlaat R, Pisters R, Lane DA, Crijns HJGM. Refining clinical risk stratification for predicting stroke and thromboembolism in atrial fibrillation using a novel risk factor-based approach. Chest. 2010;137(2):263-272. https://doi.org/10.1378/chest.09-1584.

15. Gage BF, Yan Y, Milligan PE, et al. Clinical classification schemes for predicting hemorrhage: results from the National Registry of Atrial Fibrillation (NRAF). Am Heart J. 2006;151(3):713-719. https://doi.org/ 10.1016/j.ahj.2005.04.017.

16. Hart RG, Diener HC, Yang S, et al. Intracranial hemorrhage in atrial fibrillation patients during anticoagulation with warfarin or dabigatran: the RE-LY trial. Stroke 2012;43(6):1511-1517. https://doi.org/10.1161/ STROKEAHA. 112.650614.

17. Hankey GJ, Stevens SR, Piccini JP, et al. Intracranial hemorrhage among patients with atrial fibrillation anticoagulated with warfarin or rivaroxaban: the rivaroxaban once daily, oral, direct factor Xa inhibition compared with vitamin $\mathrm{K}$ antagonism for prevention of stroke and embolism trial in atrial fibrillation. Stroke 2014;45(5):1304-1312. https://doi.org/10.1161/STROKEAHA.113.004506.

18. Smith EE, Shobha N, Dai D, et al. A risk score for in-hospital death in patients admitted with ischemic or hemorrhagic stroke. J Am Heart Assoc. 2013;2(1):e005207. https://doi.org/10.1161/JAHA.112.005207. 
19. Dachs RJ, Burton JH, Joslin J. A user's guide to the NINDS rt-PA stroke trial database. PLoS Med. 2008;5(5):e113. https://doi.org/10.1371/ journal.pmed.0050113.

20. Smith EE, Shobha N, Dai D, et al. Risk score for in-hospital ischemic stroke mortality derived and validated within the Get With The Guidelines-Stroke program. Circulation. 2010;122(15):1496-1504. https://doi.org/10.1161/CIRCULATIONAHA. 109.932822.

21. Busl KM, Prabhakaran S. Predictors of mortality in nontraumatic subdural hematoma. J Neurosurg. 2013;119(5):1296-1301. https:// doi.org/10.3171/2013.4.JNS122236.

22. Guerrouij M, Uppal CS, Alklabi A, Douketis JD. The clinical impact of bleeding during oral anticoagulant therapy: assessment of morbidity, mortality and post-bleed anticoagulant management. J Thromb Thrombolysis. 2011;31(4):419-423. https://doi.org/10.1007/s11239-0100536-7.

23. Ashburner JM, Go AS, Reynolds $\mathbf{K}$, et al. Comparison of frequency and outcome of major gastrointestinal hemorrhage in patients with atrial fibrillation on versus not receiving warfarin therapy (from the ATRIA and ATRIA-CVRN cohorts). Am J Cardiol. 2015;115(1):40-46. https://doi. org/10.1016/j.amjcard.2014.10.006.

24. Fang MC, Go AS, Chang $\mathbf{Y}$, et al. Death and disability from warfarinassociated intracranial and extracranial hemorrhages. Am J Med. 2007;120(8):700-705. https://doi.org/10.1016/j.amjmed.2006.07.034.

25. Fang MC, Go AS, Chang $\mathbf{Y}$, et al. Long-term survival after ischemic stroke in patients with atrial fibrillation. Neurology 2014;82(12):1033-1037. https://doi.org/10.1212/WNL.0000000000000248.

26. Murphy SL, Kochanek KD, Xu J, Heron M. Deaths: Final data for 2012. Natl Vital Stat Rep. 2015;63(9):1-117.

27. HCUP Databases. Healthcare Cost and Utilization Project (HCUP). Agency for Healthcare Research and Quality. Available at: www.hcup-us.ahrq. gov/sidoverview.jsp. Accessed: 26 Nov 2018.

28. Gage BF, Cardinalli AB, Albers GW, Owens DK. Cost-effectiveness of warfarin and aspirin for prophylaxis of stroke in patients with nonvalvular atrial fibrillation. JAMA. 1995;274(23):1839-1845. https:// doi.org/10.1001/jama.274.23.1839.

29. Hong KS, Saver JL. Quantifying the value of stroke disability outcomes: WHO Global Burden of Disease Project disability weights for each level of the modified Rankin scale * Supplemental Mathematical Appendix. Stroke. 2009;40(12):3828-3833. https://doi.org/10.1161/ STROKEAHA.109.561365.

30. Bureau of Labor Statistics, May 2011. Occupational employment statistics, U.S. Department of Labor. Available at: https://www.bls.gov/oes/ tables.htm. Accessed 26 Nov 2018.

31. GoodRx.com. Available at: https://www.goodrx.com. Accessed 26 Nov 2018.
32. Luengo-Fernandez R, Paul NLM, Gray AM, et al. Population-based study of disability and institutionalization after transient ischemic attack and stroke: 10-year results of the Oxford Vascular Study. Stroke. 2013;44(10):2854-2861. https://doi.org/10.1161/STROKEAHA.113. 001584.

33. Friberg L, Rosenqvist M, Lip GYH. Net clinical benefit of warfarin in patients with atrial fibrillation: a report from the Swedish Atrial Fibrillation Cohort Study. Circulation. 2012;125(19):2298-2307. https://doi.org/10.1161/CIRCULATIONAHA.111.055079.

34. Kimmel SE, French B, Kasner SE, et al. A pharmacogenetic versus a clinical algorithm for warfarin dosing. N Engl J Med. 2013;369(24):22832293. https://doi.org/10.1056/NEJMoa1310669.

35. Barnes GD, Gu X, Haymart B, et al. The predictive ability of the CHADS2 and CHA2DS2-VASc scores for bleeding risk in atrial fibrillation: the MAQI(2) experience. Thromb Res 2014;134(2):294-299. https://doi.org/ 10.1016/j.thromres.2014.05.034.

36. Azoulay L, Dell'Aniello S, Simon TA, Langleben D, Renoux C, Suissa S A net clinical benefit analysis of warfarin and aspirin on stroke in patients with atrial fibrillation: a nested case-control study. BMC Cardiovasc Disord. 2012;12(1):49. https://doi.org/10.1186/1471-2261-12-49.

37. Siegal D, Yudin J, Kaatz S, Douketis JD, Lim W, Spyropoulos AC. Periprocedural heparin bridging in patients receiving vitamin $\mathrm{K}$ antagonists: systematic review and meta-analysis of bleeding and thromboembolic rates. Circulation. 2012;126(13):1630-1639. https://doi.org/10. 1161/CIRCULATIONAHA.112.105221.

38. Le Heuzey $\mathbf{J Y}$, Ammentorp B, Darius $\mathbf{H}$, et al. Differences among western European countries in anticoagulation management of atrial fibrillation. Thromb Haemost. 2014;111(5):833-841. https://doi.org/10. 1160/TH13-12-1007.

39. Luengo-Fernandez R, Yiin GSC, Gray AM, Rothwell PM. Populationbased study of acute- and long-term care costs after stroke in patients with AF. Int J Stroke. 2013;8(5):308-314. https://doi.org/10.1111/j. 1747-4949.2012.00812.x.

40. Historical exchange rates tool \& Forex history data | OFX. Available at: https://www.ofx.com/en-us/forex-news/historical-exchange-rates/. Accessed 26 Nov 2018.

41. Ubel PA, Jagsi R. Promoting population health through financial stewardship. N Engl J Med. 2014;370(14):1280-1281. https://doi.org/ 10.1056/NEJMp1401335.

42. Kopec JA, Finès $\mathbf{P}$, Manuel DG, et al. Validation of population-based disease simulation models: a review of concepts and methods. BMC Public Health. 2010;10(1):710. https://doi.org/10.1186/1471-2458-10710. 